\title{
LA SEXUALIDAD EN MUJERES CON DISCAPACIDAD. PERFIL DE SU DOBLE DISCRIMINACIÓN
}

\author{
ASUNCIÓN MOYA MAYA
}

Universidad de Huelva

Recibido: 17/02/2009

Aceptado: 28/05/2009

\section{Introducción}

Antes de iniciar la reflexión sobre esta relación, mujer y discapacidad, y su repercusión en un ámbito concreto del desarrollo personal como es la sexualidad, creemos necesario hacer una referencia, a modo de aclaración, sobre este concepto que estamos manejando.

En 1980, la Organización Mundial de la Salud (OMS) publicó una Clasificación Internacional de Deficiencias, Discapacidades y Minusvalías (CIDDM), y en ella se definía la Discapacidad como:

Cualquier restricción o ausencia de la capacidad funcional para realizar actividades cotidianas en la forma o dentro del margen que se considera normal a un ser humano. Las discapacidades son siempre consecuencia de alguna deficiencia, pero éstas a veces no producen discapacidad, por lo que podríamos decir que hay más deficiencias que discapacidades. Las discapacidades representan trastornos funcionales a nivel de la persona.

Como se señala desde la OMS, discapacidad y deficiencia son términos asociados pero no idénticos. Si nos referimos a deficiencia, la propia OMS hace referencia a las anormalidades de la estructura corporal y de la apariencia, y a la función de un órgano o sistema, cualquiera que sea su causa; en principio, las deficiencias representan trastornos a nivel de órgano. Sin embargo, el concepto de discapacidad hace alusión al proceso por el cual una limitación funcional se manifiesta como una realidad en la vida diaria, con lo cual el problema se hace objetivo al interferir las actividades consideradas como habituales. 
Sin embargo, es importante precisar que una misma deficiencia se puede vivir con diferentes grados de discapacidad dependiendo de factores tanto personales (edad, género, salud, economía, cultura, etc,) como contextuales (ambiente familiar, actitudes sociales, accesibilidad del contexto, oportunidades laborales, etc.), por ello es esencial que hablemos de personas con discapacidad y no de discapacitados o discapacitadas.

\section{Mujer y discapacidad: una doble discriminación}

Entre los factores que, como hemos indicado en el apartado anterior, pueden condicionar las vivencias y las limitaciones de la discapacidad, está el género, por ello podríamos cuestionarnos:

¿Existen diferencias en este concepto cuando nos referimos a hombres o mujeres?

¿Es necesario considerar la discapacidad en función del género?

¿Es diferente (en función del género) el trato que la sociedad da a las personas con discapacidad?

La respuesta a estas cuestiones es afirmativa y ello nos lleva a considerar que estamos frente a un importante déficit democrático ante el cual debemos actuar.

\subsection{Análisis de la situación de las mujeres con discapacidad}

No podemos unificar este grupo de personas, ya que además de los diferentes tipos, grados y situaciones cambiantes a lo largo de todo el ciclo vital -desde niñas a mujeres mayores-, atraviesan todas las clases sociales y las diferentes identidades culturales de nuestro país.

Según la Convención Internacional sobre los Derechos de las Personas con discapacidad (Naciones Unidas, 2006), alrededor del 10\% de la población mundial, o sea 650 millones de personas vive con una discapacidad. Constituyen la mayor minoría del mundo. En la mayoría de los países de la OCDE, se observa una incidencia mayor de discapacidad sobre las mujeres que sobre los hombres

Si nos centramos en España, en la última encuesta oficial realizada sobre el tema ${ }^{1}$, el número total de personas con discapacidades en España era 3.528.221. Lo que representa un 9\% de la población, en su mayor parte compuesto por mujeres (2.055.251, un 58\%; frente a 1.472 .970 varones).

1. Fuente: Encuesta de Discapacidades, Deficiencias y Estado de Salud, 1999-INE, Fundación ONCE e IMSERSO, en adelante EDDES. 


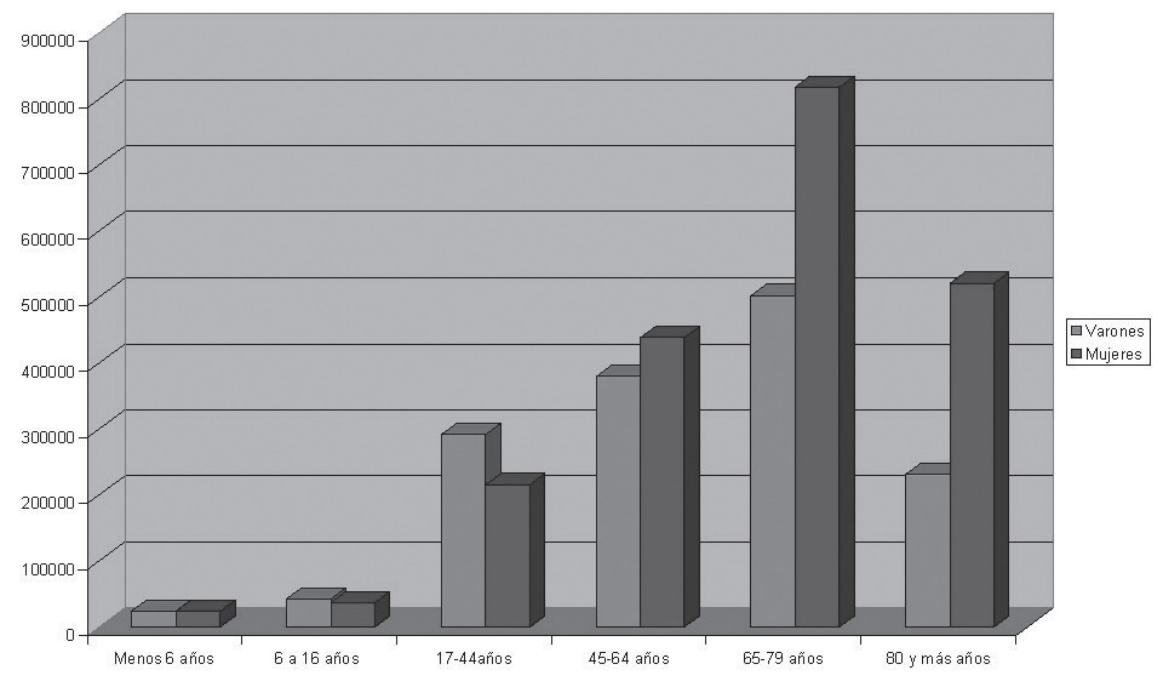

Encuesta IMSERSO 2004

Se trata de una realidad que afecta a más de dos millones de mujeres, que se encuentran en situación de mayor vulnerabilidad y muchas de ellas en riesgo de exclusión social.

El Plan de acción para las mujeres con discapacidad ${ }^{2}$ nos indica que alrededor de medio millón de mujeres con discapacidad en nuestro país viven recluidas en sus domicilios: sin apenas poder de decisión en el ámbito familiar, sin participación en los ámbitos laborales o públicos, sin posibilidad de llevar una vida autónoma, con carencias de carácter asistencial, agravadas por la edad avanzada y por asumir casi en exclusiva la función de cuidadoras de sus progenitores.

En dicho Plan se nos hace una descripción de la situación de estas mujeres en relación con la edad, estado civil, formación, empleo, entre otras variables. Presentamos algunos de los datos que nos aportan y que definen perfiles claros de discriminación:

- Las mujeres con discapacidad constituyen el 58\% del total de personas con discapacidad, siendo a partir de los 65 años el grupo mayoritario, diferencia que se incrementa en personas mayores de 80 años, de las cuales el $69 \%$ son mujeres frente al $31 \%$ de hombres.

2. Aprobado por el Consejo de Ministros de España el 1 de diciembre de 2006 el Plan de Acción para las mujeres con discapacidad 2007. Inspirado en el I Plan Integral de Acción para Mujeres con Discapacidad, que el 18 de mayo aprobó el Comité Español de Representantes de Personas con Discapacidad (CERMI). 
- En relación con el estado civil de las personas con discapacidad, las viudas representan el 39\% del total de mujeres con discapacidad, frente al 9\% de los hombres viudos con discapacidad. Por lo que se refiere al matrimonio, las mujeres casadas son un $45,2 \%$ del total de mujeres, frente a un $67,30 \%$ de los hombres que se encuentran en este estado.

- El 74,79\%, de las mujeres con discapacidad o carece de estudios o tiene estudios primarios: El porcentaje de analfabetismo causado por razones distintas a los problemas estrictamente físicos o psíquicos afecta al $6,74 \%$ de mujeres con discapacidad (43.410), frente al 3,66\% de hombres. (23.463). EDDES

- La tasa de actividad de las mujeres con discapacidad ${ }^{3}$ (21,7 \%) es menor a la de las mujeres globalmente consideradas (44\%) y menor que la de los hombres con discapacidad (34\%).

- La tasa de paro de las mujeres con discapacidad ${ }^{4}(19,70 \%)$ es tres puntos y medio superior a la de las mujeres sin discapacidad $(16,20 \%)$ y casi siete puntos superior a la de los hombres con discapacidad (12,80\%).

- Existe una brecha considerable en relación con los hombres con discapacidad en los indicadores de impacto de las medidas de fomento de empleo. De 43.088 personas con discapacidad beneficiadas, sólo 12731 son mujeres, es decir, sólo el 29.54\%. EDDES

- Un análisis del perfil de las personas que perciben pensiones no contributivas $^{5}$, denota un claro predominio de las mujeres: el 73,46\% del total. Dicho de otro modo, el número de mujeres con PNC's triplica el número de hombres. .

- El análisis cruzado en función de la capacidad para el desempeño de las actividades de la vida diaria, tanto básicas como instrumentales, muestra los mayores niveles de dependencia. Del total de personas que necesitan de ayuda para el desempeño de las actividades instrumentales de la vida diaria el $65,4 \%$ son mujeres. EDDES.

- Las principales usuarias del sistema sanitario son las mujeres con discapacidad. El 61\% de las personas que padecen enfermedades de alta dependencia son mujeres y no tienen acceso a una asistencia sanitaria adecuada. EDDES.

3. Datos de la Encuesta de Población Activa EPA 2005.

4. Las personas con discapacidad y su relación con el empleo con datos de la Encuesta de población activa, del $2^{\circ}$ trimestre del año 2002, INE, 2003.

5. Mapa de Prestaciones de naturaleza no contributiva, IMSERSO 2004. 
- Entre los grupos de gran dependencia o dependencia severa, el 63\% de las personas dependientes son mujeres con discapacidad frente al $37 \%$ de hombres. EDDES.

- Las mujeres con discapacidad apenas participan en los ámbitos de poder de la sociedad a pesar de ser mayor su participación en asociaciones. Por ejemplo, no llegan a la mitad las asociaciones que cuentan con una presidenta, siendo un $20 \%$ en el caso de las asociaciones de personas con discapacidad sensorial ${ }^{6}$.

- Estas breves notas permiten deducir que las mujeres con discapacidad constituyen un grupo considerable de personas, que se encuentran en el umbral de la pobreza, y que ejemplifican, junto a otros colectivos, el rostro del fenómeno de la feminización de la pobreza en nuestro país.

Pero además de esta situación injusta y discriminadora, resaltamos la «invisibilidad». Efectivamente, si otras situaciones discriminantes y discriminadoras son denunciadas, reflejadas en medios de comunicación, defendidas por grupos de ciudadanos... ¿es así en el caso de la mujer con discapacidad? "¿qué discrimina más, el género o la discapacidad?, ¿cómo se sienten las mujeres con discapacidad ante el trato, que en general, les da la sociedad?»

Como señala en el documento «Indicadores de exclusión social de mujeres con discapacidad» de la Asociació Dones no Estándars ${ }^{7}$, uno de los primeros intentos de poner en relación el género con la discapacidad son los trabajos de Jo Campling ${ }^{8}$. Su enfoque supone un giro a la perspectiva médica ya que entre sus aportaciones destacan el intento de ubicar la discapacidad en un contexto social, dejando que las propias mujeres discapacitadas hablen de su condición.

Estamos de acuerdo con los planteamientos que aseguran que la causa de la situación de exclusión social de la mujer con discapacidad se debe buscar en ciertos valores masculinos dominantes en las sociedades capitalistas. Estamos en un sistema de valores andróginos que promueven que los hombres con discapacidad intenten aspirar a los roles tradicionales de masculinidad. La mujer con discapacidad, por lo contrario, no tiene tal opción y se la considera económicamente improductiva en sus roles tradicionales de domesticidad (reproducción y tareas del hogar). La mujer discapacitada, frente a esta negación de rol, experimenta su discapacitación con relación a sus grupos

6. Plan Integral de Acción para Mujeres con Discapacidad, 2007, p. 14.

7. ASSOCIACIÓ DONES No ESTÀNDARDS. Indicadores de exclusión social de mujer con discapacidad. Barcelona, 2002. (Disponible en: http://sid.usal.es/)

8. Campling, Jo. Better Lives for Disabled Women. Virago Handbooks. London, UK, 1981: Images o/ ourselves: women disabilities tal king. 
minoritarios de referencia: los hombres discapacitados y las mujeres no discapacitadas. Esta situación es definida como de doble discriminación, que se ve reflejada en la exclusión social, política y económica de las mujeres con discapacidades.

Otro trabajo a resaltar es el llevado a cabo por Jenny Morris ${ }^{9}$, que ofrece una perspectiva feminista de la experiencia de la discapacidad. Morris hace una crítica al modelo masculino dominante y rescata las aportaciones del movimiento de las personas con discapacidad a la sociedad en general. Para esta autora, el prejuicio puede materializarse en múltiples formas sociales. Por lo tanto, argumenta que la situación de exclusión social de las mujeres con discapacidades no se debe explicar solamente en términos de barreras arquitectónicas, sino que es necesario tener en cuenta que el hecho de entrar en la vida pública conlleva actitudes de pena y hostilidad. Estas barreras psicosociales ejercen una presión enorme sobre las mujeres con discapacidades cuando intentan autorrealizarse, más allá de las discapacidades. Entendiendo que éste es el primer y principal obstáculo a superar para mejorar la situación de exclusión social de las mujeres con discapacidades.

\section{Un perfil de la discriminación: la vida afectiva y sexual}

Esta doble discriminación se manifiesta en realidades tan objetivas y evidentes como el empleo, salarios inferiores, menor acceso a los servicios de salud, mayores carencias educativas, mayor riesgo de sufrir violencia de género, ...

En el Plan Integral que estamos citando, se abordan diferentes esferas de exclusión y discriminación hacia la mujer con discapacidad: imagen y prejuicios, salud, vida familiar, relaciones y maternidad, violencia, protección social y jurídica, educación, poder y participación, así como empleo. Podríamos abordar cualquiera de estas áreas, citando y describiendo situaciones de evidente y constante exclusión.

En esta ocasión nos vamos centrar en un perfil de esta discriminación, pero ni por asomo el único: la vida afectiva y sexual. Aunque en los últimos años ha cobrado importancia la necesidad de integrar este sector de la población a todas las esferas de la vida cotidiana, en nuestro país los proyectos destinados a tal fin se han centrado principalmente en propiciar mayores opciones y oportunidades educativas para lograr su integración laboral, dejando de lado el reconocimiento a sus derechos sexuales y reproductivos, situación que sólo en pocas ocasiones ha sido abordada.

9. MORRIS, Jenny. Encuentros con desconocidas. Barcelona, Nancea, 1997. 
Estos son los motivos que nos han llevado a desarrollar más ampliamente este aspecto: su poco reflejo, su invisibilidad, su olvido; pues rara vez se llevan a cabo estudios o programas enfocados a su desarrollo personal.

Esta invisibilidad, como se señala en el I Plan Integral de acción para mujeres con discapacidad (2005-2008), tiene su origen y la causa en la visión que se suele tener sobre la discapacidad: la ausencia de necesidades sexuales. Durante muchos años, estas personas se han considerado como no aptas para vivir en pareja y tener hijos o hijas.

\subsection{La realidad sexual de las mujeres con discapacidad. Mitos y prejuicios}

Esta situación suele estar fundamentada en el estereotipo que afirma la condición dependiente y asexuada de las mujeres por su diferencia corporal. Como indica el propio $\mathrm{CERMI}^{10}$, se puede apreciar una influencia de la discapacidad en la imagen corporal de la mujer. Este cuerpo, en la mayoría de las ocasiones, no se ajusta a los cánones de belleza femeninos que los medios de comunicación crean y difunden, y según este Comité, hace que en muchas circunstancias, las mujeres con discapacidad encuentren mermada su autoestima y que repercuta negativamente en sus relaciones sociales y afectivas.

Tenemos que indicar que aunque esta realidad se radicaliza en la mayoría de mujeres que tienen alguna discapacidad, es una situación generalizable a todas nosotras que con el pasar de los años, las formas alejadas de la juventud... parece (o al menos los medios de comunicación, la moda, nos lo quiere hacer ver) que es feo o enfermo lo que es constitutivo de la edad, de una vida.

Hacer con nuestros cuerpos y nuestro dinero el caldo gordo a una industria cosmética y quirúrgica que engrosa el capital gracias a los complejos que se consigue desarrollar en las mujeres, al definir como feo o enfermedad algo

10. El Comité Español de Representantes de Personas con Discapacidad, más conocido por sus siglas, CERMI, es la plataforma de representación, defensa y acción de los ciudadanos españoles con discapacidad, más de tres millones y medio de personas, más sus familias, que conscientes de su situación de grupo social desfavorecido, deciden unirse, a través de las organizaciones en las que se agrupan, para avanzar en el reconocimiento de sus derechos y alcanzar la plena ciudadanía en igualdad de derechos y oportunidades con el resto de componentes de la sociedad. El I Plan de acción integral para mujeres con discapacidad es aprobado por este organismo en 2005 y marca el punto de referencia clave en materia de política social de las necesidades y demandas de las personas, hombres y mujeres, con discapacidad. Este I plan enfatiza en : la formación, la violencia de género, la salud, la maternidad, la sexualidad, los medios comunicación e imagen, la participación y el liderazgo.

Feminismo/s 13, junio 2009, pp. 133-152 
que es constitutivo de nuestros cuerpos sanos, convirtiéndolos en fuente de sufrimiento y tortura; en objeto de consumo u lucha sin fin. ${ }^{11}$

Estas concepciones y representaciones culturales sobre la imagen de la mujer, más o menos real, y su relación con la sexualidad, deriva en considerar a las personas con discapacidades como asexuadas y enfermas y se sustentan en una serie de mitos tales como la ausencia de control sobre su propia sexualidad o su supuesta incapacidad para tener una actividad sexual satisfactoria. Sobre las mujeres con discapacidades recae también con mayor énfasis las contradicciones, como hemos indicado, que todas tenemos entre la imagen real y la que se nos presenta como deseable en la publicidad, medios de comunicación y en la moda.

Las propias familias pueden llegar a favorecer esta percepción. En los aspectos afectivos y sexuales, muchas veces en el interior de los hogares se asume que las mujeres con discapacidad son seres asexuados. No se entiende que tenga deseos sexuales y necesidades afectivas de pareja, las familias desconfían mucho de quienes se acerquen a ellas por temor a que sean burladas y engañadas.

Las mujeres con discapacidad llegan a sentir vergüenza de sí mismas, y temen la turbación que puede suponer el tenerlas como pareja. Según Ángeles Cozar $^{12}$, la vergüenza social que supone el tener una pareja así, para una mayoría de la población, al menos para las personas convencionales es una gran barrera. Indica esta autora:

La salud y la sexualidad no están tratadas. A la mujer con discapacidad no se le reconoce una sexualidad propia. Al no ser consideradas mujeres deseables, se supone que tampoco desean. Primero se ve la discapacidad, no a la mujer. Una vez superada esa fase, la mujer tiene inseguridad por no encajar en los esquemas tradicionales. La influencia de madres y abuelas en niñas con minusvalías ha sido terrible. Les han inculcado que sólo se acercan a ellas para aprovecharse.

Si a esto se suman los obstáculos de accesibilidad, ya sea en una consulta ginecológica como en los posibles lugares de relación (discotecas, bares, excusiones...), se obtiene un mapa de las dificultades a las que una mujer con discapacidad se enfrenta para desarrollar plenamente su sexualidad, contribuyendo esta situación a una disminución de su autoestima.

11. FreIXA, Ana: «Hermosamente maduras. ¿Barbies a los 50?, ¡no gracias!». Revista Mujeres y Salud, 3(1999), p. 2.

12. CozAR, Maria Ángeles. «Estamos empezando a ser visibles». Revista Meridian, 2003 pp 28-29. 
El punto de vista que relaciona la sexualidad con la reproducción se une a otro mito, fruto de una perspectiva cultural, que expresa que el sexo es fuente de peligro y por ello se piensa que a las personas con discapacidad hay que protegerlas, especialmente a las mujeres. De esta manera estas personas no son consideradas aptas para la reproducción, menos aún se piensa que son capaces de vivir el sexo para el placer.

Es necesario separar los derechos sexuales de los reproductivos. Los derechos sexuales se relacionan con la libertad sexual, la salud sexual, la autonomía, la privacidad, el placer, la libertad respecto a su cuerpo..., y aunque no podemos dejar de señalar grandes avances y cambios sociales respecto a la educación sexual y a una vieja reivindicación por parte de las mujeres, su libertad para decidir tener o no hijos y su control del cuerpo, aún falta mucho por hacer en referencia a la formulación de políticas sociales, educativas, sanitarias que abarquen a «todas» las mujeres en su diversidad. En ocasiones, estas propuestas dejan fuera o se «olvidan» de algunos grupos de mujeres, como es el caso de las mujeres con discapacidad.

Este «olvido» se refleja en multitud de situaciones y lamentables episodios que las mujeres con discapacidad reflejan en sus manifestaciones. El problema es que no siempre se las tienen presentes cuando se hace planes y actuaciones de planificación familiar o de educación sobre salud sexual. No en todos los casos legisladores y profesionales de los diferentes sectores educativos, sanitario, etc, tienen conocimiento de las necesidades y características que de forma especial presentan estas mujeres. No se trata sólo de ofrecer consejos y cuidados relativos a la reproducción y a las enfermedades de transmisión sexual, sino como indica el I Plan que venimos citando,

Las niñas, jóvenes y mujeres con discapacidad necesitan tener acceso a la educación afectivo-sexual para poder vivirla saludablemente.

Deben alcanzar conocimientos sobre el funcionamiento del cuerpo, cómo se produce un embarazo y cómo se puede evitar, cómo hacer que la relación sexual sea más comunicativa y placentera, cómo oponerse a prácticas que no se desean, cómo evitar enfermedades de transmisión sexual... Privarlas de educación sexual es exponerlas a una mayor vulnerabilidad.

Es una necesidad que recoge el propio Manifiesto de las Mujeres con Discapacidad en Europa ${ }^{13}$, afirmando que las mujeres con discapacidad deben tener acceso a los métodos de planificación familiar, así como a la información al funcionamiento sexual de su cuerpo siendo indispensable que dicha información esté disponible en formatos diferentes y accesibles que garanticen su

13. Adoptado en Bruselas el 22 de febrero de 1997 y editado por el Fondo Europeo de la Discapacidad. Accesible en: <www. observatoriodeladiscapacidad.es>. 
adecuada recepción por parte de las interesadas, o sea facilitada por expertos y expertas en la materia, tales como educadores de los servicios sociales públicos locales.

Todas las mujeres tienen derecho a métodos anticonceptivos gracias a los cuales una relación erótico-afectiva no implica necesariamente tener hijos. Negar este derecho es no reconocer la capacidad de las personas a adaptarse a sus propias circunstancias. Sin embargo, aún hoy, amplios sectores sociales aún ve a las mujeres con discapacidad como inútiles, que no pueden soñar ni pensar en parejas, matrimonio, hijos o familia, por ser incapaces de manejar su vida de manera independiente.

Muchas personas con discapacidad pueden tener hijos o hijas y, como el resto, es posible que deseen usar la anticoncepción temporalmente. Otros tal vez deseen un método anticonceptivo permanente o de acción prolongada, ya que tener y criar hijos o hijas puede resultarles difícil. Quizás algunas prefieran un método permanente si sufren de una condición genética que podrían heredar sus hijos o hijas. Pero en el caso de querer tener hijos/as, muchos son los obstáculos, tabúes y faltas graves a los derechos esenciales, que deben sobrellevar las personas con discapacidad que desean formar una familia, y cómo siempre, de entre las personas agraviadas destacan las mujeres.

Señala el citado I Plan Integral:

«el miedo al embarazo y sus consecuencias (considerar que no tienen habilidades y/o medios suficientes para cuidar de una criatura, las repercusiones físicas para la madre, el miedo a que pueda heredar la discapacidad) han sido durante años de historia la gran preocupación de familias y cuidadoras de las mujeres con discapacidad $»^{14}$

Dado que la sociedad no incluye a las personas con discapacidad dentro de los cánones tradicionales de paternidad y pareja, la temática no asciende a los organismos sociales y gubernamentales. Por ejemplo, existen muchos casos de parejas con discapacidad física notoria que desean adoptar un niño o niña y raramente son tenidos en cuenta como potenciales padres por parte de los jueces. Por otra parte, la paternidad o la sexualidad en personas con discapacidad mental es un tema en el que ni siquiera se piensa. Recogemos las palabras de mujeres con discapacidad, dentro del programa de «Derechos reproductivos y mujeres discapacitadas» coordinado por María del Pilar Cruz Pérez, ${ }^{15}$ sobre los conflictos en relación a la maternidad, los cuales, comienzan en el seno mismo de la familia.

14. I Plan de Acción Integral para las Mujeres con Discapaciad. Op.cit, p. 174.

15. CRuz PÉrez, María Pilar. «Mujeres con discapacidad y su derecho a la sexualidad». Política y cultura, 22 (2004) pp. 147-160. 
Según Lucía, la gente se sorprende porque rompes esquemas:

A mi propia familia le dije que yo quería tener hijos y me dijeron que no, que era peligroso... que pensara en realizarme de otra manera.... Mi familia no sólo se extrañó cuando les hablé de la posibilidad de tener hijos, sino que se ofendieron. Mi propio médico se negaba a asesorarme, a todos les parecía terrible mi decisión.

Cuando hablo de que tengo vida sexual suelen pasar dos cosas: o les parezco rarísima, irresponsable y pervertida, o me admiran por mi entereza. A lo mejor soy muy chocante pero no me gusta ninguna de las dos posturas», compartía Marisa en su testimonio.

Pero también esto sucede en ámbitos profesionales, como podemos ver en palabras de Sofía:

Una tiene mucho contacto con los médicos y en general se sorprenden si les pides información ginecológica o de anticonceptivos. Te ven con cara de asombro. Abundan las miradas de sorpresa o de lástima de todo el mundo. Los médicos, las enfermeras, los que hacen los análisis, todos te bombardean: que deberías pensar en abortar, que si hay quién te ayude en la casa, que si eres una irresponsable... de cuando en cuando tienes que pedirles que no se metan en lo que no les importa o hacer como que no oyes y aguantarte.

Lamentablemente, una realidad que no podemos pasar por alto en esta temática, es la situación de víctimas de violación y abusos sexuales que muchas sufren. Algunos estudios, como el de Iglesias $^{16}$, afirman que la mujer con discapacidad se encuentra en riesgo mayor que una mujer sin discapacidad de padecer un abuso sexual o violencia doméstica. El referenciado documento de la Associació Dones No Estàndards cita a Fine y Asch afirmando que una mujer con discapacidad es una «víctima fácil» de abuso por parte de personal de atención sanitaria, compañeros de hogar o de aquellos hombres de los cuales pueden ser dependientes económicamente.

La propia Organización Mundial de la Salud reconoce que el acceso limitado y el escaso control que las mujeres tienen sobre su propia sexualidad las

16. IGLESIAS, Marita. Informe sobre Violencia y Discapacidad. A Coruña, Asoc. IES, 1998 (disponible en www.asoc-ies.org).

IGLESIAS Marita y CERMI. I plan integral de acción para mujeres con discapacidad 20052008. Datos recogidos por la Disabled Women's Network (DAWN) de Toronto (1995) sostiene que «en Canadá, mas de un millón de mujeres tiene discapacidad, de las que 670.000 han sido física o sexualmente agredidas antes de la pubertad (2 veces más que las mujeres sin discapacidad) y 330.000 han padecido agresiones sexuales y físicas siendo ya adultas (una de cada tres frente a una de cada cuatro en mujeres sin discapacidad)» (Informe «Violencia: mujer y discapacidad», 1998). 
convierten en seres vulnerables a la explotación sexual, a la violencia, a los embarazos no deseados y las enfermedades de transmisión sexual.

Para contemplar el alcance de esta afirmación de la OMS, no podemos olvidar que cuando nos referimos a violencia lo hacemos desde la propia definición de la $\mathrm{ONU}^{17}$, cuando la define como: cualquier acto de violencia basado en el género que produzca, o acabe produciendo, resultados de daño físico, psíquico o sexual o sufrimiento en la mujer, incluyendo amenazas de tales actos, coacción o privación arbitraria de libertad, ocurriendo todo esto tanto en el ámbito público como privado.

Basándonos en ella, la violencia comprende desde los actos «típicamente» violentos (maltrato físico, agresión sexual,...) hasta otros actos basados en actitudes y prácticas discriminatorias. Por ello debemos entenderla también como la subordinación y desprecio a que se somete a un ser humano debido a su condición, por el hecho de ser mujer y además tener una discapacidad. Es decir, hay formas comunes de abusos que están relacionadas directamente con la discapacidad.

Estas situaciones de segregación, discriminación, invisibilidad que en muchos casos las mujeres seguimos padeciendo, creemos que siguiendo la propia definición de la ONU, son en sí mismas actos de violencia que generan frustración y agresión en la víctima. Pero, si a ello le sumamos las propias realidades y limitaciones que impone una discapacidad, nos encontramos ante niveles de violencia y vulnerabilidad agudizados e intolerables.

No se sabe mucho de la violencia contra las mujeres con discapacidad. La violencia es diversa. La sexual es muy frecuente en el hogar. Se da hasta el silencio, que es la primera de las violencias. Pocas denuncias de malos tratos contra la mujer con discapacidad salen a la luz. También se da el maltrato psicológico, y la violencia de la dependencia para comer, vestirse, asearse. En la vida cotidiana no se trata igual a la mujer que al hombre con discapacidad ${ }^{18}$.

Tendríamos que reflexionar y ponernos en la piel de estas mujeres. Son un grupo de altísimo riesgo y con una especial desprotección, pues en ellas concurren determinadas situaciones que las hacen especialmente vulnerables cuando viven situaciones de violencia. Como recoge el propio Instituto Andaluz de la Mujer ${ }^{19}$, ¿hemos pensado que ellas tienen...

17. La Organización de Naciones Unidas (ONU) en su Artículo 1. de la Declaración sobre la eliminación de la violencia contra la mujer, 1993.

18. CozAr, Maria Ángeles. Op.cit, p. 23.

19. Instituto ANDALUZ De La MuJER: Violencia hacia las mujeres con discapacidad. Guía informativa, 2003. 
- mayores dificultades (o imposibilidad total) a la hora de defenderse físicamente?

- mayores dificultades (o imposibilidad total) para expresar los malos tratos?

- en ocasiones dificultad (o imposibilidad total) de acceso a los centros de información y asesoramiento principalmente debido a la existencia de todo tipo de barreras físicas y de comunicación?

- una mayor dependencia (o absoluta) de la asistencia y cuidados de otros?

- miedo a denunciar el abuso por la posibilidad de la pérdida de los vínculos y la provisión de cuidados?

- menor credibilidad a la hora de denunciar hechos de este tipo ante algunos estamentos sociales?

- mayor riesgo de abusos severos y frecuentes sobre aquellas mujeres que tienen una multideficiencia, problemas de desarrollo mental y de comunicación?

No queremos olvidar que estas manifestaciones están definidas desde la globalidad y de forma general. Evidentemente no todas las mujeres con discapacidad sufren esta situación, y además hay muchos aspectos sociales y personales que van a condicionar algunos perfiles de violencia (estado físico, tipo y grado de la discapacidad, salud emocional, situación social y económica...) pero tampoco es definitorio, al igual que tampoco lo son, en el resto de las mujeres que sufren la violencia de género. ${ }^{20}$

Quisiéramos en este momento reflexionar sobre una forma de violencia consentida y de alto contenido ético: se trata de la esterilización.

Resulta estremecedor que entre 1992 y 1997, según recoge Cruz Pérez ${ }^{21}$, 1.045 niñas discapacitadas menores de 18 años fueron esterilizadas por la fuerza en Australia. Incluso niñas de ocho años fueron esterilizadas por razones que incluyen la eliminación de la menstruación y la prevención del embarazo. Como sucedió en Cánada, donde la Corte de Apelaciones de Columbia Británica consideró que un cirujano podía realizar una histerectomía a una niña discapacitada de 10 años sin la autorización de los padres, con el argumento de que anticipaba una reacción adversa a la menstruación.

20. Ver, entre otros: FerreirA, G.B. Hombres violentos, mujeres maltratadas: Aportes a la investigación y tratamiento de un problema social. Buenos Aires, Sudamericana, 1995; Sarasua, B. y Zubizarreta, L. Violencia en la pareja. Málaga, Aljibe, 2000; VArela, N. Íbamos a ser reinas. Mentiras y complicidades que sustentan la violencia contra las mujeres. Barcelona, Ediciones B, 2002.

21. Cruz Përez. Op. cit, p.11. 
Son variados y muy graves los casos que se han denunciado en todo el mundo. Cuando acercamos la lupa al tremendo daño que la falta de información y los prejuicios causan a las personas con discapacidad, sabemos que esos mismos daños afectan a toda la sociedad.

El Comité Español de Representantes de Personas con Discapacidad (CERMI), nos indica tajantemente, en su I Plan de Acción Integral ${ }^{22}$ que:

nunca se debe esterilizar a una mujer en contra de su voluntad, y si la persona en cuestión no estuviera capacitada para dar su consentimiento, dicha esterilización tan sólo debe aplicarse en caso de clara necesidad por causas médicas y previa aprobación judicial.

\subsection{Cuerpos diferentes pero con derecho a la sexualidad}

Debemos reflexionar sobre derechos que reconocen y garantizan el respeto a la libertad sexual, a la salud sexual, a la autonomía, a la integridad y seguridad sexual del cuerpo, a la privacidad, al placer, a la expresión sexual emocional, a la libre asociación, a la toma de decisiones reproductivas libres y responsables, a la información basada en el conocimiento científico y a la educación sexual integrada, entre otros.

Frente a la medicalización de la sexualidad, es necesario, insistir en la construcción de alternativas a estas tendencias, buscando en las posibilidades que dan la educación y la información para colocar el debate sobre la sexualidad más allá del campo médico.

La salud sexual y reproductiva no sólo entra en la perspectiva de lo clínico; involucra sobre todo las capacidades de disfrutar de una vida sexual plena, sin riesgos, que ampara la posibilidad de generar vida y elegir libremente el modo y los plazos. Cada logro que se construya en relación a ampliar y enriquecer las miradas y las acciones de salud reproductiva, como también la accesibilidad, el trabajo y la educación, será un beneficio para la sociedad entera y no para una minoría.

Todavía quedan muchos escollos por superar: aún no hay un consenso internacional respecto a una definición de discapacidad. Sabemos que las discapacidades son, muchas veces, construcciones culturales y sociales y la mayor parte de la terminología que prevalece es fuente de muchas controversias. Por otro lado, parece que las propias Administraciones empiezan a considerar y plantear la necesidad de acciones en este sentido. El Plan de Acción para las Mujeres con discapacidad 2007 del Ministerio de Trabajo y Asuntos Sociales,

22. I Plan Integral de Acción para Mujeres con Discapaciad. Op.cit, p. 192. 
plantea una serie de actuaciones y de objetivos en el sentido que venimos analizando:

- Promover el reconocimiento del derecho a la sexualidad de las mujeres con discapacidad.

Para ello se proponen la realización de investigaciones relacionadas, por un lado, con el conocimiento y desarrollo del derecho a la sexualidad de las mujeres con discapacidad que se encuentren en centros residenciales, y por otro, con las diferentes ayudas técnicas a todas las mujeres con discapacidad, pero en particular, a aquellas que presentan determinadas necesidades tanto cognitivas, mentales como de comunicación.

- Facilitar el desarrollo del derecho a las relaciones afectivas de las mujeres con discapacidad.

En relación a este objetivo, el citado Plan ve necesaria la realización de una investigación sobre el tipo de relaciones de pareja existentes, que permita desarrollar programas de actuación y campañas de sensibilización y encuentros en el movimiento asociativo de personas con discapacidad y de mujeres con discapacidad.

- Garantizar el derecho de las mujeres con discapacidad al libre desarrollo de la maternidad.

Para este amplio objetivo, se proponen medidas en consonancia con lo que se ha desarrollado en este artículo, como serían: programas de planificación familiar específicos, que tengan en cuenta las diversas necesidades y decisiones de las mujeres respecto a la interrupción voluntaria de su embarazo, facilitación del acceso a los sistemas de reproducción asistida, sensibilizando a las/los profesionales implicados en el proceso y haciendo accesible el propio sistema.

Es necesaria la promoción de la creación de puntos de información y ayuda mutua entre mujeres con discapacidad que quieran ser madres y aquellas que ya lo han sido.

En el caso de optar por la maternidad, este Plan indica la necesidad de revisar los baremos de ingreso en las escuelas infantiles de los hijos e hijas de mujeres con discapacidad, así como la promoción de servicios de proximidad para su atención y cuidado.

Además de estas medidas, el citado Plan hace indicaciones sobre la necesidad de sensibilizar e informar y formar a los profesionales que actúan en los procesos de custodia y adopción para que no se produzcan situaciones discriminatorias. Indica, así mismo, la necesidad de una atención multiprofesional destinada a resolver los problemas que se puedan presentar ante las 
exigencias de la maternidad, como asegurar ingresos mínimos a las madres con discapacidad, entre otras.

El recientemente aprobado Plan de Acción Integral para Mujeres con Discapacidad en Andalucía ${ }^{23}$ incluye como una de las áreas prioritarias la de salud y derechos sexuales y reproductivos. Esta área temática afronta aquellos elementos a tener en cuenta para lograr la equidad en el acceso a una atención sanitaria de calidad, así como en el ejercicio de derechos esenciales como la maternidad o el desarrollo de una vida sexual plena.

Este Plan se propone como objetivo:

Favorecer la superación de las barreras para que las mujeres con discapacidad reciban una atención sanitaria adaptada a sus necesidades, fomentando el conocimiento de los aspectos específicos relacionados con su salud, posibilitando el desarrollo de su derecho a la sexualidad y la maternidad, habilitando los recursos necesarios e impulsando la formación de los equipos médicos en género y discapacidad. ${ }^{24}$

En cuanto a las medidas que desarrollan este objetivo, se recogen las siguientes:

1. Elaboración de estudios con perspectiva de discapacidad y género sobre las necesidades de salud integral de las mujeres con discapacidad.

2. Investigación sobre diversas formas de desarrollo y expresión de la sexualidad en mujeres con discapacidad.

3. Impulso de programas de prevención y promoción de la salud dirigidos a mujeres con discapacidad, que contemplen acciones de información y sensibilización sobre los derechos y recursos de salud existentes.

4. Dotación de instrumental y aparatos de exploración adaptados y accesibles a todo tipo de mujeres con discapacidad, en especial a las mujeres con discapacidad física en las mesas de exploración ginecológica, acceso al equipo de radiología, etc.

5. Desarrollo de protocolos específicos sobre sexualidad y planificación familiar, diferenciados por tipos de discapacidad y adaptados al estilo de vida de las mujeres con discapacidad, para potenciar su responsabilidad en la propia salud reproductiva y sexual.

6. Formación de profesionales de la salud sobre mujer y discapacidad, para una atención diferenciada y que garantice un trato digno a las mujeres con discapacidad.

23. Plan de acción integral para mujeres con discapacidad en Andalucía (2008-2013). Publicado en el BOJA el 11 de noviembre de 2008.

24. Plan de acción integral..., Op.cit., p. 173. 
7. Incluir en la formación que se imparte a los profesionales del sistema de protección, vinculados con procesos de acogimiento y adopción conocimientos y pautas de actuación para que no se produzcan situaciones discriminatorias.

8. Dar prioridad, en los centros socioeducativos y los servicios para la atención y cuidado de la infancia, a los hijos e hijas de las mujeres con discapacidad, con el fin de garantizar la integración social y laboral de las mismas.

9. Diseño de programas de planificación familiar específicos, que tengan en cuenta las diversas necesidades en función de los distintos tipos de discapacidad, incluyendo la garantía de autonomía de las mujeres en la toma de decisiones.

10. Promoción de actuaciones que favorezcan la información y ayuda mutua entre mujeres con discapacidad que quieran ser madres y aquellas que ya lo han sido.

11. Dotación de los recursos técnicos y humanos necesarios para eliminar las barreras en la comunicación en los servicios sanitarios, garantizando la atención a las personas con discapacidad, especialmente a las mujeres, en condiciones de igualdad, así como una atención adecuada durante el periodo de embarazo y en el parto, evitando, en la medida de lo posible, partos inducidos.

12. Fomento de actividades de información, asesoramiento, apoyo y formación, dirigidas a las propias mujeres con discapacidad, a sus padres y madres y a los y las profesionales de los servicios de atención directa, para que promuevan el desarrollo de una sexualidad sana en las niñas y mujeres con discapacidad.

13. Adaptación de planes, procesos y programas de atención a la salud a las especificidades de las mujeres con discapacidad, asegurando su acceso equitativo.

Éstas son las intenciones. Desearíamos que dentro de poco pudiésemos escribir reflejando realidades. Todos y todas, de alguna manera, tenemos responsabilidad en el reconocimiento actual de la sexualidad como un derecho natural, sin diferencias en el caso de personas con limitaciones y discapacidades. Como indica la Carta de derechos sexuales en favor de los minusválidos promulgada en 1982, todos y todas tienen y tenemos:

1. Derecho a la expresión sexual.

2. Derecho a la intimidad.

3. Derecho a ser informados. 
4. Derecho a poder acceder a los servicios necesarios, como son el asesoramiento sobre anticonceptivos, atención médica, asesoramiento genético y sobre sexualidad.

5. Derecho a escoger el estado civil que más convenga al discapacitado.

6. Derecho a tener, o no, hijos.

7. Derecho a tomar las decisiones que afectan la vida de cada uno.

8. Derecho a intentar el desarrollo de todo el potencial del individuo.

Queremos finalizar esta aportación mostrando la foto ${ }^{25}$ y las palabras de Alison Lapper. Quizás en su reflexión esté el sentido de lo que hemos estado exponiendo.

«Mi cuerpo es bello. No estoy acomplejada». Alison va con la cabeza bien erguida. Los músculos de su cuello son poderosos y tiene un torso y unos pechos esculturales. Se parece a la Venus esculpida en el mármol de Milo. «A ella nunca le reprocharon ser una minusválida. ¿Por qué, entonces, me lo reprochan a mí sin cesar? He aprendido a amarme sola».

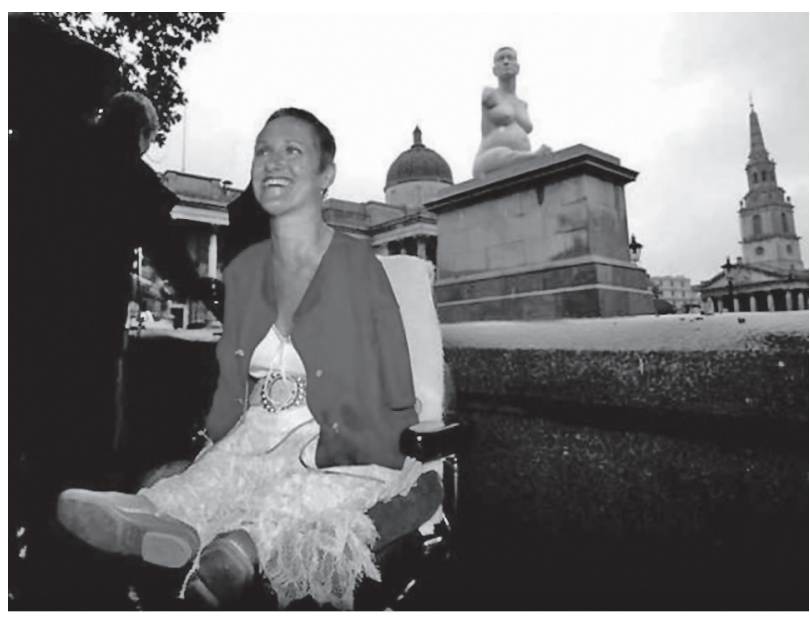

25. La plaza londinense de Trafalgar Square cuenta con una estatua que sirve de contrapunto a la columna del almirante Nelson: la efigie de 3,6 metros de altura y 11,5 toneladas de mármol blanco de una mujer minusválida, desnuda y embarazada, «Alison Lapper embarazada», esculpida por Marc Quinn, quien dijo que había hecho la escultura de su amiga porque las personas minusválidas no están suficientemente representadas en el arte. De hecho la obra de arte ha dividido las opiniones de críticos y defensores de los minusválidos. 


\section{Referencias bibliográficas}

AsSociació DONES No EstàndARDS. Indicadores de exclusión social de mujer con discapacidad. Barcelona, 2002. (Disponible en: http://sid.usal.es/)

CozAR, M. A. «Estamos empezando a ser visibles». Revista Meridian, 2003, pp. 28-29.

Cermi. I Plan Integral de acción para mujeres con discapacidad (2005-2008): Aprobado por el Comité Ejecutivo del CERMI Estatal el 18 de mayo de 2005. <http://www. cermi.es/NR/rdonlyres/2F461565-A061-4D89-8361-7487CA16EE26/2209/ Libro188905.pdf>.

Cruz Pérez, M. P. «Mujeres con discapacidad y su derecho a la sexualidad». Política y cultura, 22 (2004), pp. 147-160.

FERREIRA, G. B. Hombres violentos, mujeres maltratadas: Aportes a la investigación y tratamiento de un problema social. Buenos Aires, Sudamericana, 1995.

FrEIXA, A.: «Hermosamente maduras. ¿Barbies a los 50?, ¡no gracias!». Revista Mujeres y Salud, 3 (1999), pp. 2-3.

IGLESIAS, M. Informe sobre Violencia y Discapacidad. A Coruña. Asoc. IES, 1998. (Disponible en: www.asoc-ies.org)

Instituto ANDAluz DE la Mujer: Violencia hacia las mujeres con discapacidad. Guía informativa (2003).

Junta De Andalucía. Plan de Acción Integral para Mujeres con Discapacidad en Andalucía 2008-2013 (BOJA, 11 noviembre 2008). http://www.juntadeandalucia.es/compromisos20082012/archivos_repos/0/202.pdf

Ministerio De TRABajo y Asuntos Sociales: Plan de acción para las mujeres con discapacidad 2007 (aprobado en el Consejo de Ministros de 1 de Diciembre de 2006). <http://www.seg-social.es/imserso/normativas/pamcd2007.pdf>.

MORRIS, J. Encuentros con desconocidas. Barcelona, Lancea, 1997.

Riu, C. (coord.). Indicadores de Exclusión Social de Mujer con Discapacidad, Barcelona, Ed. Dones No Estàndards, 2002.

Sarasua, B. y Zubizarreta, L. Violencia en la pareja. Málaga, Aljibe, 2000.

VARIOS. Violencia y la mujer con discapacidad, 2002. <www.asoc-ies.org/docs/indiexso_muj_dis.pdf>.

VARELA, N. Íbamos a ser reinas. Mentiras y complicidades que sustentan la violencia contra las mujeres. Barcelona, Ediciones B. 2002. 